\title{
Gluteal subcutaneous calcifications on a patient with chronic back pain
}

Key words: calcification, granuloma, injection-site reaction, subcutaneous fat, computed tomography

A middle-aged man presented to the emergency department with a three-day history of macroscopic haematuria and mild discomfort on his right lower back. He denied fever or other urinary complaints. His past medical history was significant for chronic low back pain, benign prostatic hyperplasia, and obesity, for which a bariatric surgery was performed 21 years earlier. In face of the clinical suspicion of nephrolithiasis, a computed tomography scan of the abdomen was ordered, confirming the hypothesis by showing nonobstructive micro calculi on the lower pole of the right kidney.

Surprisingly, though, multiple bilateral subcutaneous calcifications were seen on the gluteal region (Fig. 1). When questioned, the patient affirmed having received intragluteal injections of non-steroidal anti-inflammatory drugs (NSAIDs) and corticosteroids multiple times in the past for his low back pain.

A diagnosis of injection site granuloma was made. There is no data on the literature about the prevalence of subcutaneous calcification on the gluteal region secondary to inadvertent injection of an intramuscular drug on the fat tissue, with reports having been published about granuloma formation after administration of several medications, such as opiates, NSAIDs [1], leuprorelin [2] and Sandostatin [3].

However, given that about half of the intended intramuscular injections are mistakenly applied subcutaneously [4], injection site granuloma may not be a highly uncommon entity. Its importance resides on the possible differential diagnosis with more severe con-

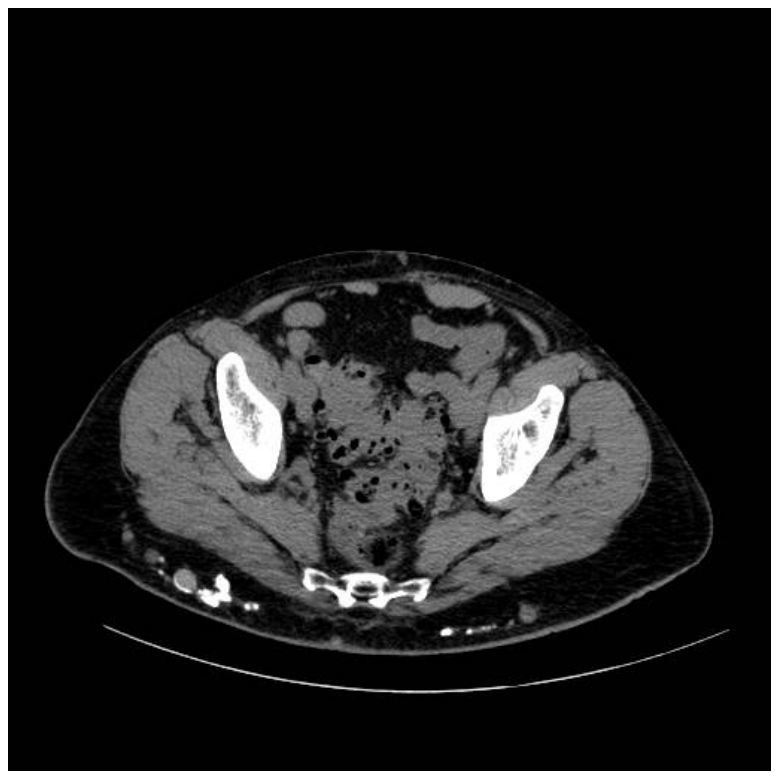

Figure 1. Axial scan of CT of abdomen evidencing welldemarcated lesions on the subcutaneous fat tissue, either fully or rim calcified

ditions, such as soft-tissue sarcoma, dermatomyositis and systemic sclerosis.

Bilaterality and lesion stability over time speaks against malignancy. The absence of muscle weakness or typical skin lesions makes dermatomyositis quite unlikely. For systemic sclerosis, one would expect an antecedent of the Raynaud phenomenon, sclerodactyly 
and digital ulcers. Heterotopic ossification usually has an identifiable trigger event, such as a history of trauma or joint replacement surgery. Accurate history taking may lead to the final diagnosis, obviating further workup [5].

\section{References}

1. Prosch H, Mirzaei S, Oschatz E, et al. Case report: Gluteal injection site granulomas: false positive finding on FDG-PET in patients with non-small cell lung cancer. Br J Radiol. 2005; 78(932): 758-761, doi: 10.1259/bjr/55106848, indexed in Pubmed: 16046432.
2. Thway K, Strauss DC, Smith MJ, et al. Foreign body granulomas induced by intramuscular leuprorelin acetate injection for prostate cancer: clinical mimics of soft tissue sarcoma. Case Rep Oncol Med. 2015; 2015: 947040, doi: 10.1155/2015/947040, indexed in Pubmed: 25918659.

3. Rideout DJ, Graham MM. Buttock granulomas: a consequence of intramuscular injection of Sandostatin detected by In-111 octreoscan. Clin Nucl Med. 2001; 26(7): 650, doi: 10.1097/00003072-20010700000025, indexed in Pubmed: 11416760.

4. Boyd AE, DeFord LL, Mares JE, et al. Improving the success rate of gluteal intramuscular injections. Pancreas. 2013; 42(5): 878-882, doi: 10.1097/MPA.0b013e318279d552, indexed in Pubmed: 23508015.

5. Su YJ, Lai YC. Gluteal injection site granuloma. J Emerg Med. 2012; 43(1): 121-122, doi: 10.1016/j.jemermed.2010.06.031, indexed in Pubmed: 20926224. 